\title{
Preparation and Characterization of Chitosan/ $\beta$-cyclodextrin Nanoparticles Containing Plasmid DNA Encoding Interleukin-12
}

Authors

Affiliations
M. Nahaei ${ }^{1}$, H. Valizadeh ${ }^{2}$, B. Baradaran ${ }^{3}$, M. R. Nahaei ${ }^{4}$, D. Asgari ${ }^{2}$, S. Hallaj-Nezhadi ${ }^{1}$, S. Dastmalchi ${ }^{5}$, F. Lotfipour ${ }^{1}$

Affiliation addresses are listed at the end of the article
Key words

- chitosan

- $\beta$-cyclodextrin

- plasmid

- nanoparticle

- interleukin-12

received $\quad 06.06 .2012$

accepted 30.10 .2012

\section{Bibliography}

DOI http://dx.doi.org/

10.1055/s-0032-1331165

Published online:

January 8, 2013

Drug Res 2013;

63: 7-12

(c) Georg Thieme Verlag KG Stuttgart · New York

ISSN 2194-9379

\section{Correspondence}

F. Lotfipour

Faculty of Pharmacy

Tabriz University of Medical

Sciences

54664 Tabriz

Iran

Tel.: + 98/411/3392580

Fax: + 98/411/334 4798

lotfipoor@tbzmed.ac.ir

\section{Abstract}

$\nabla$

Background: Interleukin-12 (IL-12) as a cytokine has been proved to possess antitumor effects via stimulating the immune system. Nonviral gene delivery systems offer several advantages, including easiness in production, low cost, safety; low immunogenicity and can carry higher amounts of genetic material without limitation on their sizes.

Methods: pUMVC3-hIL12 loaded Low Molecular Weight chitosan/ $\beta$-cyclodextrin (LMW CS/ $\mathrm{CD}$ ) nanoparticles were prepared using ionotropic gelation method and characterized in terms of size, zeta potential, polydispersity index, morphology, loading efficiency and cytotoxicity against the CT-26 colon carcinoma cell line.

\section{Introduction}

$\nabla$

Nanoparticle-based drug delivery systems offer numerous privileges including targeting the drug into the potential active site, thus decreasing its side effect, controlling the release of the drug at the active site and increasing the drug uptake. Also they produce some excellent pharmacokinetic properties leading to enhance the drug absorption and distribution. Application of nanoparticles in the delivery of nucleotides into their active sites has been the subject of several researches in the past few decades [1]. Gene therapy, as a new and promising way to treat some of most complicated health disorders, is defined as the transfer of a genetic material into a cell for therapeutic benefits [2]. Generally, there are 2 types of gene delivery systems including viral and non-viral. Although viral gene delivery systems possess high efficiency in various human tissues, they have some limitations like immunogenicity, toxicity and possible viral gene integration into the human genome. On the other hand,
Results: All prepared particles were spherical in shape and nano-sized $(171.3 \pm 2.165 \mathrm{~nm}$, PdI: $0.231 \pm 0.014)$ and exhibited a positive zeta potential $(34.3 \pm 1.55)$. The nanoparticles demonstrated good DNA encapsulation efficiencies (83.315\% \pm 2.067$)$. Prepared pUMVC3-hIL12 loaded LMW CS/CD nanoparticles showed no cell toxicity in murine CT-26 colon carcinoma cells. At the concentration of $0.1 \mu \mathrm{g} / \mathrm{ml}$ of nanoparticles, the transfection ability was obviously higher than that of the naked DNA.

Conclusion: LMW CS/CD-plasmid DNA nanoparticles encoding IL-12 prepared using ionotropic gelation method with no toxic effect on the tested cells can be considered as a basis for further gene delivery studies both in vitro and in vivo to enhance the expression of IL-12.

non-viral systems (including physical and chemical approaches), have lower toxicity and immunogenicity. In addition, manipulation and preparation of non-viral delivery systems are easier in comparison with those of viral $[3,4]$. The most important non-viral vectors are cationic lipids and cationic polymers which produce condensed complexes with negatively charged DNA (lipoplexes and polyplexes). The complexes protect DNA and facilitate cell uptake and intracellular delivery $[5,6]$. Of the cationic polymers investigated so far, chitosan has been introduced as a potential gene carrier. Chitosan is a linear biodegradable, biocompatible, non-allergenic and nucleic acid bindingable polysaccharide composed of randomly distributed N-acetyl-Dglucosamine and $\beta$ - $(1,4)$-linked D-glucosamine. Chitosan generates a positively charged complex in interaction with DNA leading to enhanced cellular interaction and uptake. Chitosan can swirl across the membrane bilayer and facilitate the cellular uptake of the polyplex [1]. In spite of the main advantages of chitosan polyplexes, their 
capacity to efficiently deliver the gene of interest into cells is still limited. It can be due to some reasons such as undefined physical shapes, dissociation of the complexes in the presence of anions and a limited capacity to co-associate other functional molecules [7]. Cyclodextrins are a family of cyclic oligosaccharides which consists of $(\alpha-1,4)$-linked $\alpha$-D-glucopyranose unit with a hydrophilic outer surface and a lipophilic central cavity [8]. Cyclodextrins present many advantages as potential core molecules for the development of nonviral vectors [9-13]. Indeed new generations of polysaccharide nanocarriers consisting of chitosan and cyclodextrins have been developed in recent years to use the promising behavior of chitosan nanoparticles with the excellent biopharmaceutical properties of cyclodextrin [7]. The objective of the present study was to prepare chitosancyclodextrin-plasmid DNA nanoparticles encoding interleukin-12 that has been proved to possess antitumor effects via stimulating the immune system. Also the physicochemical characteristic as well as cytotoxicity of the prepared formulations were evaluated against the CT-26 colon carcinoma cell line.

\section{Materials and Methods}

\section{$\nabla$}

\section{Materials}

PUMVC3-hIL12 (Aldevron, Fargo, ND, USA), Chitosan (CS) MW 190-310 kDa 75-85\% degree of deacetylation, Beta cyclodextrin (CD), 3-(4, 5-dimethylthiazol-2-yl)-2, 5 -diphenyl tetrazolium bromide (MTT), Lipofectamine ${ }^{\mathrm{TM}} 2000$ Transfection Reagent (Invitrogen, Carlsbad, CA, USA), Kanamycin, Glycin, Trypan blue solution, Penicillin and streptomycin (Sigma-Aldrich, Munich, Germany), Ethylene diamine tetraacetic acid (EDTA), Tris base, Luria-Bertani broth (LB), Acetic acid (HAc), Sodium Acetate (NaAc), Tripolyphosphate (TPP) (Merck, Darmstadt, Germany), Endotoxin-free plasmid gigaprep Kit (Qiagen, Santa Clarita, CA, USA), Fetal bovine serum (FBS), RPMI-1640, (Gibco, Invitrogen Inc., Burlington, Ontario, Canada), Murine CT-26 colon carcinoma cells (National Cell Bank, Pasteur Institute, Iran).

\section{Preparation and characterization of low molecular weight chitosan}

The low molecular weight CS (LMW CS) was prepared by oxidative degradation with $\mathrm{NaNO}_{2}$ at room temperature. Briefly, $1 \%$ $(\mathrm{w} / \mathrm{v})$ CS was dissolved in $1 \%$ HAc solution, consequently an appropriate amount of $0.1 \mathrm{M} \mathrm{NaNO}_{2}$ was added dropwise and the reaction was performed at room temperature for $3 \mathrm{~h}$ and $24 \mathrm{~h}$, respectively. The reaction mixture was subsequently neutralized with $1 \mathrm{~N} \mathrm{NaOH}$ to $\mathrm{pH} 8.0$ to precipitate CS. The precipitated CS was recovered by centrifugation, washed several times with deionized water, and dried [14]. Viscosities of prepared CS

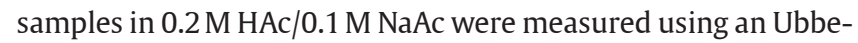
lohde capillary viscometer (Model Schott mainz, Germany) in a constant-temperature of $30 \pm 0.01^{\circ} \mathrm{C}$. Solution concentrations were adjusted based on the viscosity of the samples and the flow through time was kept in the range of 100-150 s. 5 different concentrations were tested for each sample. The intrinsic viscosity was determined by the intercept of Huggins $(\mathrm{nsp} / \mathrm{C} \sim \mathrm{C})$ plot on the ordinate at $\mathrm{C}=0$. Finally the molecular weight of each sample was calculated based on the classical Mark-Houwink equation: $[\eta]=K\left(M_{\mathrm{V}}\right)^{\text {a }}$. Where $[\eta]$ is the intrinsic viscosity of the depolymerized CS, $K$ and $a$ are constants for given solute-solvent system and temperature. For CS, they are influenced by the degree of deacetylation, $\mathrm{pH}$, and ionic strength of the solvent [14]. Accord- ing to our solvent system ( $0.2 \mathrm{M} \mathrm{HAc} / 0.1 \mathrm{M} \mathrm{NaAc}), \mathrm{k}$ and $\alpha$ were $0.000104,0.001424$ and $1.12,0.96$ for 69 and 84 degree of deacetylation, respectively [15].

\section{Preparation of LMW CS/CD nanoparticles}

Nanoparticles were obtained by ionotropic gelation Method according to Alonso et al. [7]. 2 aqueous phases containing: (1) LMW CS solution ( $2 \mathrm{mg} / \mathrm{ml}$ ), and (2) CD solution $(20 \mathrm{mg} / \mathrm{ml}$ ) containing $3 \mathrm{mg} / \mathrm{ml}$ TPP as cross-linker, were mixed under vortexing for $10 \mathrm{~min}$. For nanoparticles encapsulating the pDNA, the required amount of the plasmid pUMVC3-hIL12 was incorporated directly into the $\mathrm{CD} / \mathrm{TPP}$ phase [7]. To this end, plasmid DNA was firstly extracted from transformed E.coli (DH5- $\alpha$ ), then the concentration of purified plasmid DNA was determined at $260 \mathrm{~nm}$ using nanodrop spectrophotometer.

Physicochemical characterization of the pUMVC3-hIL12 loaded LMW CS/CD nanoparticles

Evaluation of particle size, polydispersity index, and zeta potential of the pUMVC3-hIL12 loaded LMW CS/CD nanoparticles were performed by zetasizer nano particle analyzer (Nano ZS, Red badge, ZEN3600). Particle morphology of the selected pUMVC3-hIL12 loaded LMW CS/CD nanoparticles was determined by transmission electron microscopy (TEM). One drop of LMW CS/CD nanoparticles was placed on a copper grid and stained with $1 \%$ uranyl acetate solution for $5 \mathrm{~s}$. The grid was allowed to dry further for $10 \mathrm{~min}$ and was then examined with the electron microscope (LEO 906, Germany). The amount of plasmid DNA encapsulated in the LMW CS/CD nanoparticles was calculated by considering the difference between the total amount of DNA added into the preparation medium through the coacervation process and the amount of non-entrapped DNA remaining in the supernatant after centrifugation (12000 RPM, for $30 \mathrm{~min}$, at $4^{\circ} \mathrm{C}$ ) of prepared nanoparticles. For this purpose, the supernatant was spectrophotometrically analyzed at $260 \mathrm{~nm}$ for DNA concentration [16].

\section{Evaluation of cytotoxicity}

Cytotoxicity of the pUMVC3-hIL12 loaded LMW CS/CD nanoparticles was evaluated by the MTT based cytotoxicity assay in murine CT-26 colon carcinoma cells. MTT assay is based on the ability of living cells to reduce MTT, a water-soluble yellow dye, to a purple colored formazan precipitates product by mitochondrial reductase enzymes. The cells were seeded in a 96-well plate at a density of $5 \times 10^{4}$ cells $/ \mathrm{cm}^{2}$ in $100 \mu$ of RPMI- 1640 medium supplemented with $10 \% \mathrm{FBS}$ and incubated for $24 \mathrm{~h}$ at $37^{\circ} \mathrm{C}$ under $5 \% \mathrm{CO}_{2}$. Afterward, the medium was removed and supplied with $200 \mu \mathrm{l}$ of fresh culture medium. Subsequently, pDNA loaded LMW CS/CD nanoparticles were added to the cells at a serial dose of 1.6, 0.8, 0.4, 0.2, $0.1,0.05,0.025 \mu \mathrm{g}$ pUMVC3-mIL12/ $\mu$ l. Non-treated cells as well as and cells treated with lipofectamine ${ }^{\mathrm{TM}}$ were used as controls and incubated for the same duration of time. Following $24 \mathrm{~h}$ of incubation at $37^{\circ} \mathrm{C}$ under $5 \% \mathrm{CO}_{2}$, the medium was removed and fresh cell culture medium was added, then the cells were incubated with $20 \mu \mathrm{l}$ MTT $(0.5 \mathrm{mg} / \mathrm{ml}$ MTT in medium) for $4 \mathrm{~h}$. Subsequently the medium was removed, and the formazan precipitates formed in living cells were dissolved in $200 \mu \mathrm{l}$ DMSO and $25 \mu \mathrm{l}$ Sorenson buffer per well. Relative viability (\%) was calculated based on absorbance at $570 \mathrm{~nm}$ using an ELISA plate reader. Viability of non-treated control cells was arbitrarily defined as $100 \%$. The relative cell viability was calculated as $[\mathrm{Abs}]_{\text {sample }} /[\mathrm{Abs}]_{\text {control }} \times 100$. Data were presented as mean $\pm S D(n=4)$. 
Table 1 Viscosity measurement of $24 \mathrm{~h}$ degraded chitosan.

\begin{tabular}{|lccccc}
\hline Chitosan Conc. $(\mathbf{g} / \mathbf{m l})$ & $\mathbf{0 . 0 0 1}$ & $\mathbf{0 . 0 0 2 5}$ & $\mathbf{0 . 0 0 5}$ & $\mathbf{0 . 0 1}$ & $\mathbf{0 . 0 0 7 5}$ \\
\hline Average Flow throw Times (S) \pm SD & $98.6 \pm 1.140$ & $102 \pm 0.707$ & $109.6 \pm 0.894$ & $126.4 \pm 4.505$ & 1.404 \\
\hline Viscosity (cp) & 1.095 & 1.133 & 0.217 & 1.515 \\
\hline Specific Viscosity & 0.014 & 0.049 & 0.127 & 0.300 \\
Reduced Viscosity $(\mathrm{ml} / \mathrm{g})$ & 14.403 & 19.753 & 25.514 & 40.054
\end{tabular}

Table 2 Formulation, particle size, polydispersity index, and zeta potential of pUMVC3-hIL12 loaded LMW CS|CD nanoparticles.

\begin{tabular}{|c|c|c|c|c|c|c|c|c|}
\hline $\begin{array}{l}\text { Formu- } \\
\text { lation }\end{array}$ & $\begin{array}{l}\text { pDNA } \\
(\mu \mathrm{g} / \mathrm{ml})\end{array}$ & $\begin{array}{l}\text { Chitosan } \\
\text { (mg/ml) }\end{array}$ & $\begin{array}{l}\text { cyclodextrin } \\
(\mathrm{mg} / \mathrm{ml})\end{array}$ & $\begin{array}{l}\text { TPP } \\
(\mathrm{mg} / \mathrm{ml})\end{array}$ & $\begin{array}{l}\text { Average Particle } \\
\text { Size }^{*}(\mathrm{~nm}) \pm \text { SD }\end{array}$ & $\begin{array}{l}\text { Average Polydis- } \\
\text { persity Index } \pm \text { SD }\end{array}$ & $\begin{array}{l}\text { Average Zeta } \\
\text { Potential }(\mathrm{mV}) \pm \mathrm{SD}\end{array}$ & $\begin{array}{l}\text { Encapsulation } \\
\text { Efficiency( } \%) \pm \text { SD }\end{array}$ \\
\hline F1 & 100 & 2 & 20 & 3 & $171.3 \pm 2.165$ & $0.231 \pm 0.014$ & $34.3 \pm 1.55$ & $83.315 \pm 2.067$ \\
\hline
\end{tabular}

*Average particle size measured as Z-average after sonication

\section{In vitro transfection studies}

Murine CT-26 colon carcinoma cells were seeded into 24-well plates at a density of 80000 cells/well in $1 \mathrm{ml}$ of RPMI- 1640 medium supplemented with $10 \% \mathrm{FBS}$ and incubated for $24 \mathrm{~h}$ at $37^{\circ} \mathrm{C}$ under $5 \% \mathrm{CO}_{2}$. Prior to transfection, the medium was removed and the cells were rinsed with PBS ( $\mathrm{pH} 7.4$ ), then supplied with $900 \mu \mathrm{l}$ of RPMI- 1640 medium without FBS. The cells were incubated with pDNA loaded LMW CS/CD nanoparticles at concentrations range of 0.025 to $0.8 \mu \mathrm{g} / \mathrm{ml}$ for $6 \mathrm{~h}$ at $37^{\circ} \mathrm{C}$ under $5 \% \mathrm{CO}_{2}$. Subsequently, the serum-free medium was removed and the wells were washed with PBS. Fresh medium (RPMI-1640 containing $10 \%$ FBS) was then added to each well. The cell culture plate was incubated for another $48 \mathrm{~h}$ at $37^{\circ} \mathrm{C}$ under $5 \% \mathrm{CO}_{2}$. Non-treated cells and cells transfected with naked plasmid (as negative controls) were used and incubated for the same duration of time. All experiments were done in triplicates, with 3 separate experiments to demonstrate reproducibility.

For quantitative analysis of the pUMVC3-hIL12 expression, the human IL-12p70 enzyme-linked immunosorbent assay (ELISA) Kit was used according to the manufacturer's instructions. For this purpose, the collected culture supernatants were analyzed for the measurement of hIL-12 p70. The amount of the protein was determined as picogram per $\mathrm{ml}$.

\section{Results}

$\nabla$

Preparation and characterization of low molecular weight chitosan

The LMW CS was prepared by oxidative degradation with $0.1 \mathrm{M}$ $\mathrm{NaNO}_{2}$ at room temperature using $1 \%(\mathrm{w} / \mathrm{w}) \mathrm{CS}$ dissolved in $1 \%$ HAc solution. The molecular weight of $24 \mathrm{~h}$ degraded CS was calculated based on the classical Mark-Houwink equation as 12-32 KDa. Results related to $24 \mathrm{~h}$ degraded samples are shown in $\odot$ Table 1 and $\odot$ Fig. 1.

\section{The pUMVC3-hIL12 loaded LMW CS/CD nanoparticles formation and characterization}

LMW CS/CD nanoparticles were prepared by ionotropic gelation in the presence of TPP, as described in the methodology section. The average size, polydispersity index and Zeta potential of pUMVC3-hIL12 loaded LMW CS/CD nanoparticles are given in $\odot$ Table $\mathbf{2}$ and depicted in $\odot$ Fig. 2. Also the amount of DNA loaded in the nanoparticles was calculated as encapsulation efficiency (\%) which is shown in $\odot$ Table 2.

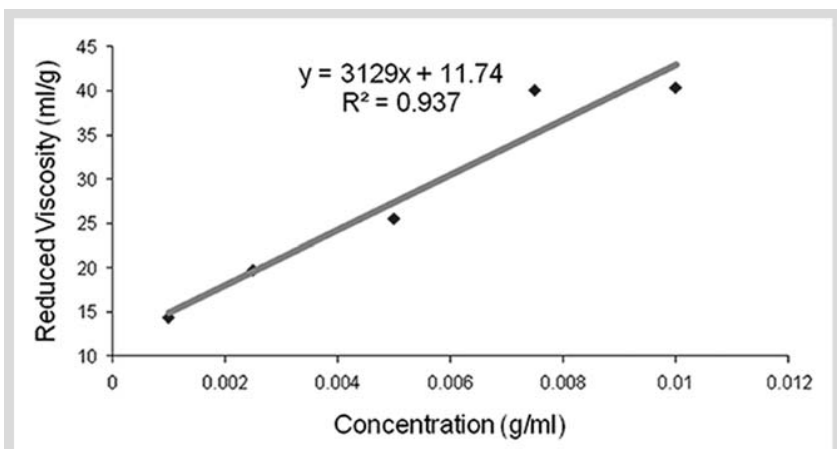

Fig. 1 Reduced viscosity vs. concentration of $24 \mathrm{~h}$ degraded chitosan.

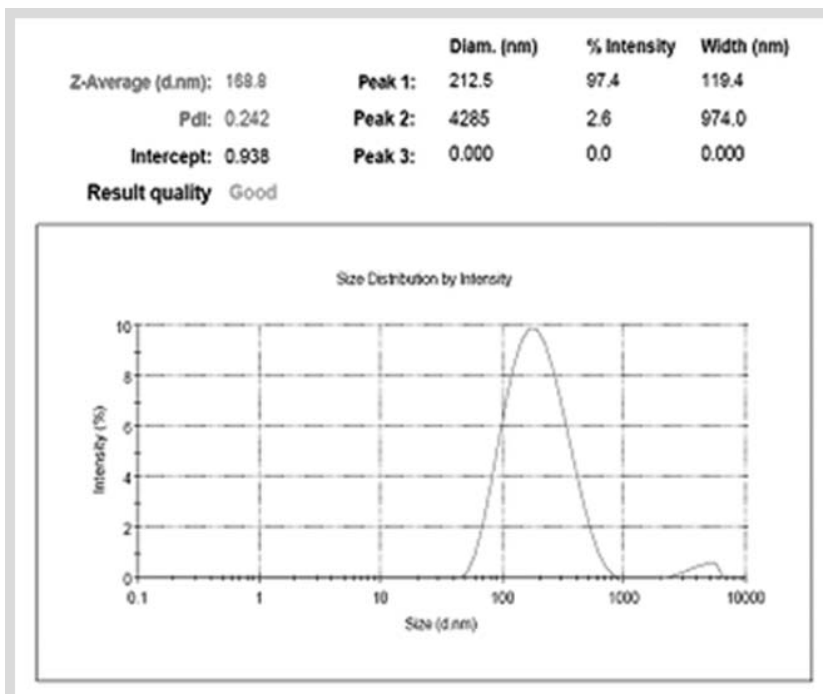

Fig. 2 Particle size distribution profiles of pUMVC3-hIL12 loaded chitosan/cyclodextrin nanoparticles.

A typical transmission electron microscopy (TEM) image of F1 is shown in $\bullet$ Fig. 3. As can be seen from this figure, the particles were nano-sized and spherical in shape.

\section{Evaluation of cytotoxicity and viability}

The cell toxicity of pUMVC3-hIL12 loaded LMW CS/CD nanoparticles was investigated by MTT-based cytotoxicity assay in murine CT-26 colon carcinoma cells. The prepared polyplexes showed no cell toxicity in murine CT-26 colon carcinoma cells. The average cell viability determined using MTT assay for 
different DNA concentrations ranged from $97.7 \pm 5$ to $126.8 \pm 23$ (๑ Fig. 4). In contrast, Lipofectamine/IL-12 complexes as a control resulted in less than $60 \%$ cell viability.

\section{In vitro transfection studies}

- Fig. 5 compares the transfection efficiencies of the pUMVC3hIL12 loaded LMW CS/CD nanoparticles in different concentrations in CT-26 carcinoma cells. Untreated CT-26 cells showed no production of Il-12. At plasmid concentrations below or above $0.1 \mu \mathrm{g} / \mathrm{ml}$, the transfection efficiencies of pUMVC3-hIL12 loaded LMW CS/CD nanoparticles were not remarkably different from that of the naked DNA. At the concentration of $0.1 \mu \mathrm{g} / \mathrm{ml}$, the transfection ability was obviously higher than that of the naked DNA.

\section{Discussion}

$\nabla$

Immunotherapy-based strategies for cancer therapy try to increase the local and systemic immune response against the cancer cells and possibly provide a less toxic approach. IL-12 has been shown to have superior antitumor activity compared to other cytokines. To get optimal results, cytokines are required to be available over an extended period of time, which is not possible with IL-12 protein owing to its short half-life [17]. According to the several studies reported in this area, polymeric vectors like CS, release their payload in a sustained manner [1]. Hence, we hypothesized that gene therapy using pUMVC3-hIL12 loaded LMW CS/CD nanoparticles possibly provide noteworthy advantages over protein therapy due to the potential ability of polymeric based nanoparticles to produce sustained levels of IL-12 in the tumor location. Based on the previous studies in this regard, LMW CS showed the ability to efficiently interact with the pDNA [7]. Thus CS in the molecular weight of 12-32 KDa prepared by oxidative degradation method was used in this study. pUMVC3-hIL12 loaded LMW CS/CD nanoparticles were prepared via ionotropic gelation method which is simple, quick, economical, and requires no toxic solvents compared to the other approaches [1]. The electrostatic interaction between positively charged CS and negatively charged DNA and CD is involved in the nanoparticle formation. Furthermore, the ability of CS to undergo a liquid-gel transition due to its ionic interaction with TPP is of importance in the process. The maximum LMW CS/CD/ TPP mass ratio to produce optimum nanoparticle characterization was chosen to be $6 / 1 / 1(\mathrm{w} / \mathrm{w}$ ) according to Teijeiro-Osorio et al. [7]. Following the preparation of the nanoparticles, they were characterized in terms of size, zeta potential, morphology, loading efficiency, cytotoxicity, and finally transfection efficiency. As shown in $\bullet$ Fig. 2, 3, all particles were nano-sized $(171.3 \pm 2.165 \mathrm{~nm}$, PdI: $0.231 \pm 0.014)$ and exhibited positive zeta potential $(34.3 \pm 1.55)$. In general, zeta potential is one of the important particle characteristics, because more pronounced zeta potential values lead to stabilization of the particle suspension due to the electrostatic repulsion between particles with the same electric charge which prevents aggregation [18]. Furthermore, the positively charged particles can facilitate adherence to negatively charged cellular membranes which will induce and increase intracellular uptake $[19,20]$. Alonso et al. prepared ionically crosslinked nanoparticles based on LMW CS (10KDa) with plasmid DNA and TPP at the same ratio of CS/TPP $(6 / 1 / 1)$. Based on their results, the size of prepared particles were in the range of $109 \pm 13$ to $165 \pm 10$ and zeta potential of

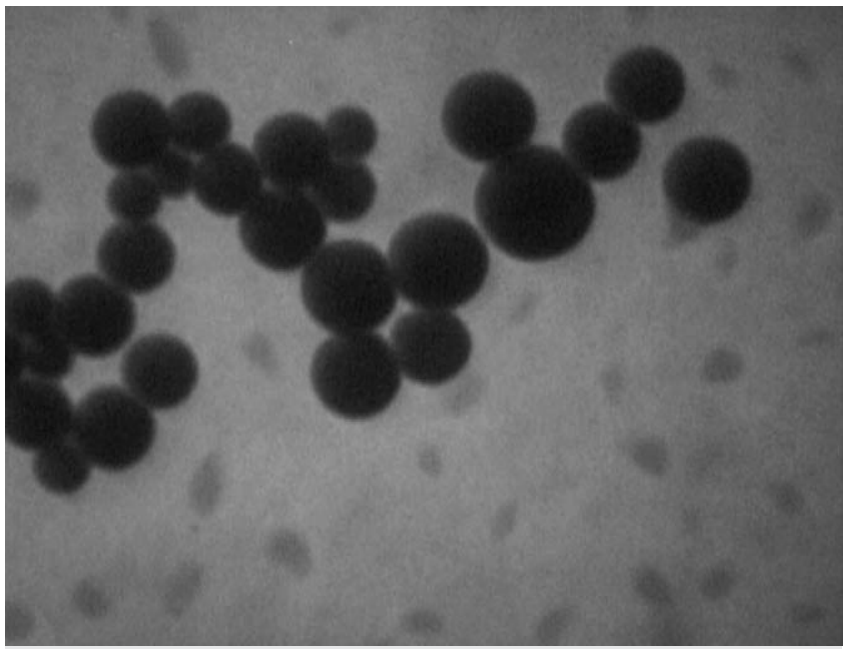

Fig. 3 Transmission electron microscopy (TEM) photograph of pUMVC3hIL12 loaded chitosan/ $\beta$-cyclodextrin nanoparticles.

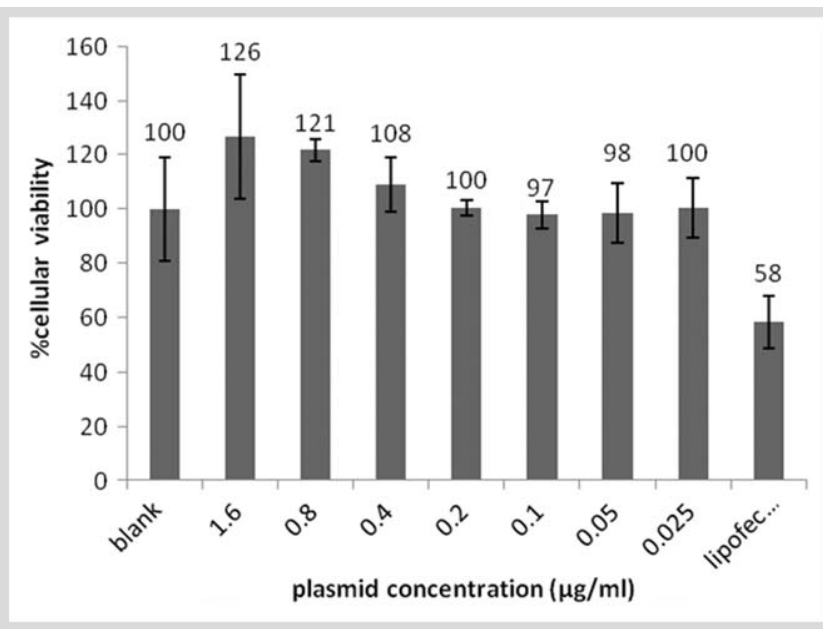

Fig. 4 Mean Viability $\pm S D(n=4)$ of $C T-26$ colon adenocarcinoma cells after treatment with pUMVC3-hIL12 loaded chitosan/ $\beta$-cyclodextrin nanoparticles by MTT assay.

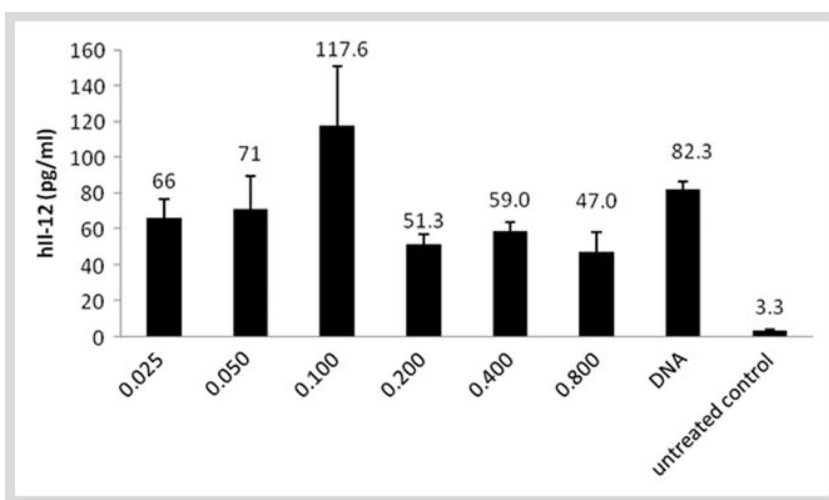

Fig. 5 Mean IL-12 expression of formulations \pm SD $(n=3)$; CT-26 colon adenocarcinoma cells were treated with chitosan/ $\beta$-cyclodextrin nanoparticles and naked plasmid DNA for $4 \mathrm{~h}$ and ELISA was performed at $48 \mathrm{~h}$ post treatment. The bars and error bars represent the hll-12 concentration and the corresponding standard deviations. Chitosan/ $\beta$-cyclodextrin nanoparticles showed maximum transfection efficiency at plasmid concentration of $0.1 \mu \mathrm{g} / \mathrm{ml}$. 
$7.7 \pm 0.4$ to $10.8 \pm 4.2$. Also in cytotoxicity test, they were non toxic. In comparison with these results and ours, it is obvious that there are no considerable differences in the physicochemical properties and cytotoxicity of LMW CS/TPP (6/1) nanoparticles with LMW CS/CD/TPP (6/1/1) nanoparticles [21].

The mean encapsulation efficiency of our prepared nanoparticles for DNA was $83.31 \%$ as shown in 0 Table 2 . The high encapsulation efficiency is observed in the previous studies for other CS nanoparticles which might be due to the high affinity of CS to DNA [22].

It is important to evaluate the toxicity of the prepared nanoparticles in a cell line model. MTT assay is a quantitative colorimetric method to determine cell proliferation and it utilizes the yellow tetrazolium salt which is metabolized by mitochondrial succinic dehydrogenase activity of proliferating cells. The ability of cells to reduce MTT provides an indication of the mitochondrial integrity and activity, which, in turn, may be interpreted as a measure of viability. Comparison of results between control and test cultures provides an indication of the cytotoxic effect of test compounds [14]. The effect of different CS derivatives as well as CS/CD complexes on the viability of tumor cells has been extensively studied so far (26-29) and some controversial results have been reported. Some studies reported no toxicity against the tested cell lines at the used concentrations, both for CS or CS/ CD complexes [7]; whereas, other studies reported the inhibition of the growth of tumor cell in the presence of CS or its derivatives $[23,24]$. Also, there are few reports about the stimulation effect of CS, for example, Dhiman and coworkers showed that the reduction percentage of MCF-7 cells brought by Tamoxifen in the presence and absence of CS are $15 \%$ and $50 \%$ respectively, indicating strong stimulation (inhibition of reduction) of the selected cell lines [25]. Also, in another study [26], the stimulation effect of CS on orchid meristem culture and orchid protocorm propagation was reported. Prepared pUMVC3-hIL12 loaded LMW CS/CD/TPP nanoparticles showed no cell toxicity with average cell viability of almost over 97\% in murine CT-26 colon carcinoma cells $(97.7 \pm 5$ to $126.8 \pm 23)$ that was significantly higher than the average cell viability of lipofectamine treated cells $(58.2 \pm 9.5)$. Even the viability percentages of the tested cells were increased by about $120 \%$ in the case of 1.6 and $0.8 \mu \mathrm{g} / \mathrm{ml}$. Having low toxicity will make it possible to increase the dose of these nanoparticles or use repeated administrations. Based on the studies reported for the in vitro release properties of polymeric vectors like CS, a sustained manner has been reported [1]. Nevertheless, the in vitro release studies can be a representative of the in vitro stability of the particles, rather than in situ release behavior. Since the intracellular release condition is completely different, so the in vitro release studies cannot mimic the real conditions inside the cells. Consequently, we decided to study the effect of our prepared nanoparticles on the expression of Il-12, as a correct way to find an idea about the intracellular release behavior as well as the transfection efficiency.

CT-26 colon carcinoma cells as cancer cells which are less immunogenic have been widely used for the study of the anti-tumor activity of IL-12. According to our results which is depicted in 0 Fig. 5, CT-26 cell as untreated control showed approximately no production of Il-12 (3.3 pg/ml). On the other hand, following $48 \mathrm{~h}$ treatment of the cells with IL-12 naked plasmid, $82.3 \mathrm{pg} / \mathrm{ml}$ of Il-12 protein was detected using ELISA Kit indicating the transfection of the cells. We tried to evaluate the trans- fection efficiencies in longer incubation times, but the best response was obtained in $48 \mathrm{~h}$.

The expression study of our prepared nanoparticles was performed by $48 \mathrm{~h}$ treatment of the cells using different plasmid concentrations. LMW CS/CD/TPP nanoparticles resulted in the highest Il-12 production in murine CT-26 at plasmid concentration of $0.1 \mu \mathrm{g} / \mathrm{ml}$. This is in agreement with the reported studies using LMW CS/TPP chitosan nanoparticles indicating that the best transfection efficiency was at an optimum pDNA loading $[7,21]$. However, there was no significant difference between the transfection efficiency of our prepared nanoparticles and the naked DNA ( $p>0.05$ ). This finding may be due to several reasons, especially the strong electrostatic interaction between CS and CD, which may prevent prompt intracellular DNA release. Indeed, due to the technical difficulties like acidity of the medium, prolonged incubation of the cells (more than $48 \mathrm{~h}$ ) was not possible. Hence, the expression amounts of Il-12 in the cells treated with the sustained release nanoparticles and naked plasmid DNA were not properly differentiated in short incubation times. Alonso et al. found that the transfection efficiency of HMW CS/TPP was higher than some versions of HMW CS/CD/ TPP and inclusion of CD into HMW CS/TPP had a negative effect in the transfection efficiency. On the other hand, in the case of nanoparticles prepared using LMW CS, addition of CD enhanced the transfection efficiency but it was not a massive change $[7,21]$.

Taken together, mild preparation process of DNA complexes using LMW CS/CD/TPP yielded the non-toxic nanoparticles with suitable physicochemical properties. Therefore the prepared LMW CS/CD nanoparticles were selected for in vitro expression studies. In the expression studies in spite of the slight increase in Il-12 at plasmid concentration of $0.1 \mu \mathrm{g} / \mathrm{ml}$, the differences between Il-12 concentration in nanoparticles and naked plasmid DNA were insignificant. Further in vivo studies should be performed using animal models to investigate the effect of the prepared LMW CS/CD nanoparticles on the IL-12 expression in real conditions.

\section{Acknowledgements}

$\nabla$

The authors thank Faculty of Pharmacy and Hematology and Oncology Research Center, Tabriz University of Medical Sciences, Iran for providing grant for the project.

\section{Conflict of Interest \\ $\nabla$}

The authors report no conflict of interest.

\footnotetext{
Affiliations

${ }^{1}$ Hematology and Oncology Research Center and Faculty of Pharmacy, Tabriz University of Medical Sciences, Tabriz, Iran

${ }^{2}$ Research Center for Pharmaceutical Nanotechnology and Faculty of Pharmacy, Tabriz University of Medical Sciences, Tabriz, Iran ${ }^{3}$ Immunology Research Center, Faculty of Medicine, Tabriz University of Medical Sciences, Tabriz, Iran

${ }^{4}$ Drug Applied Research Center, Tabriz University of Medical Sciences, Tabriz, Iran

${ }^{5}$ Biotechnology Research Center, Tabriz University of Medical Sciences, Tabriz, Iran
} 


\section{References}

1 Hallaj-Nezhadi S, Valizadeh H, Dastmalchi S et al. Preparation of chitosan-plasmid DNA nanoparticles encoding interleukin-12 and their expression in CT-26 colon carcinoma cells. J Pharm Pharm Sci 2011; 14: $181-195$

2 George JA. Gene therapy progress and prospects: Adenoviral vectors. Gene ther 2003; 10: 1135-1141

3 Schmidt-Wolf GD, Schumidt-Wolf IGH. Non-viral and hybrid vectors in human gene therapy: An update. Trends Mol Med 2003; 9: 67-72

4 Davis ME. Non-viral gene delivery systems. Curr Opin Biotech 2002; 13: $128-131$

5 Al-Dosari MS, Gao X. Nonviral gene delivery: Principle, limitations and recent progress. AAPS 2009; 11: 671-681

6 Morille M, Passirani C, Vonarbourg A et al. Progress in developing cationic vectors for non-viral systemic gene therapy against cancer. Biomaterials 2008; 29: 3477-3496

7 Teijeiro-Osorio D, Remunan-Lopez C, Alonso MJ. Chitosan/cyclodextrin nanoparticles can efficiently transfect the airway epithelium in vitro. Eur J Pharm Biopharm 2009; 71 (2): 257-263

8 Arun R, Ashok KCK, Sravanti VVNSS. Cuclodextrins as drug carrier molecule: A review. Scientia Pharmaceutica 2008; 76: 567-598

9 Zhang JT, Chua LS, Lynn DM. Multilayer thin films that sustain the release of functional DNA under physiological conditions. Langmuir 2004; 20 (19): 8015-8021

10 Jessel $N$, Oulad-Abdelghani M, Meyer $F$ et al. Multiple and time-scheduled in situ DNA delivery mediated be beta-cyclodextrin embedded in a polyelectolyte multilayer. Proc Nat Acad Sci USA 2006; 103 (23): 8618-8621

11 Irie T, Otagiri M, Sunada $M$. et al. Cyclodextrin-induced hemolysis and shape changes of human erythrocytes in vitro. J Pharmacobiodyn 1982; 5 (9): 741-744

12 Kilsdonk EPC, Yancey PG, Stoudt GW et al. Cellular cholesterol efflux mediated by cyclodextrins. J Biol Chem 1995; 270 (29): 17250-17256

13 Cryan SA, Holohan A, Donohue $R$ et al. Cell transfection with polycationic cyclodextrine vectors. Eur J Pharm Sci 2004; 21 (5): 625-633

14 Mao S, Shuai X, Unger $F$ et al. The depolymerization of chitosan: Effects on physicochemical and biological properties. Int J Pharm 2004; 281 (1-2): 45-54
15 Wang $W$, Bo S, Li S et al. Determination of the Mark-Houwink equation for chitosans with different degrees of deacetylation. Int J Biol Macromol 1991; 13 (5): 281-285

16 Mao HQ Roya K, Troung-Le VL et al. Chitosan-DNA nanoparticles as gene carrier: Synthesis, characterization and transfection efficiency. J Controlled Release 2001; 70 (3): 399-421

17 Tan J, Newton CA, Djeu JY et al. Unjection of complementary DNA encoding interleukin-12 inhibits tumor establishment at a distant site in a murine renal carcinoma model. P Am Assoc Canc Res 1996; 56: 3399-3403

18 Diez S, Migueliz I, Ilarduya CT. Targeted cationic poly (D,L-lactic-coglycolic acid) nanoparticles for gene delivery to cultured cells. Cell Mol Biol Lett 2009; 14 (2): 347-362

19 Ranaldi G, Mariglianoa I, Vespignani I et al. The effect of chitosan and other polycations on tight junction permeability in the human intestinal Caco-2 cell line. J Nutr Biochem 2002; 13 (3): 157-167

20 Bowman $K$, Leong KW. Chitosan nanoparticles for oral drug and gene delivery. Int J Nanomedicine 2006; 1 (2): 117-128

21 Csaba N, Kping-Hggard M, Alonso MJ. Ionically crosslinked chitosan/ tripolyphosphate nanoparticles for oligonucleotide and plasmid DNA delivery. Int J Pharm 2009; 382: 205-214

$22 \mathrm{Li}$ XW, Lee DKL, Chan ASC et al. Sustained expression in mammalian cells with DNA complexed with chitosan nanoparticles. Biochim Biophys Acta 2003; 1630 (1): 7-18

23 Maeda Y, Kimura Y. Antitumor effects of various low-molecularweight chitosans are due to increased natural killer activity of intestinal intraepithelial lymphocytes in sarcoma 180 -bearing mice. J Nutr 2004; 134 (4): 945-950

24 Dhiman HK, Ray AR, Panda AK. Three-dimensional chitosan scaffoldbased MCF-7 cell culture for the determination of the cytotoxicity of tamoxifen. Biomaterials 2005; 26 (9): 979-986

$25 \mathrm{Qi} L F, X u Z R$, Li Y et al. In vitro effects of chitosan nanoparticles on proliferation of human gastric carcinoma cell line MGC803 cells. World J Gastroentero 2005; 11 (33): 5136-5141

26 Nge KL, Nitar N, Chandrkrachang $S$ et al. Chitosan as a growth stimulator in orchid tissue culture. Plant Sci 2006; 170: 1185-1190 